\title{
Linguística aplicada: o processo de produção e reescrita textual na educação básica
}

\section{Applicated linguistics: the textual production and rewriting process in basic education}

\author{
Márcia Dias Kraemer* \\ Jocieli Aparecida de Oliveira Pardinho** \\ Rafaella Salvini***
}

\section{RESUMO}

Este artigo trata do processo de produção e de reescrita de texto no Ensino Médio. O objetivo do trabalho é tratar do estudo acerca da construção do conhecimento linguístico em uma perspectiva processual (Geraldi, 1997), sob a óptica da Análise Dialógica do Discurso e à luz da Linguística Aplicada. Como aporte metodológico, a pesquisa possui natureza teórico-prática, com abordagem qualitativo-interpretativa e fins explicativos. Os procedimentos técnicos correspondem à pesquisa de revisão bibliográfica, estudo de caso e pesquisa-ação. A geração de registros acontece por meio da documentação indireta bibliográfica e direta intensiva na descrição documental. O método principal de análise e de interpretação dos dados é o dialético, tendo como subsídio secundário, os procedimentos técnicos histórico, comparativo

Recebido em 23 de abril de 2020.

Aceito em 28 de junho de 2020.

DOI: http://dx.doi.org/10.18364/rc.2021n61.402

*marciakraemer@uol.com.br, Universidade Federal da Fronteira Sul - UFFS,

Orcid: 0000-0002-8780-7813

**jocielipardinho@gmail.com, Universidade Estadual do Oeste do Paraná - UNIOESTE, Orcid: 0000-0002-4451-8253

***rafaella_salvini@hotmail.com, Universidade Estadual do Oeste do Paraná - UNIOESTE, Orcid: 0000-0002-6923-1224

Confluência. Rio de Janeiro: Liceu Literário Português, n. 61, p. 434-462, jul.-dez. 2021 
e monográfico. Como resultados, propõe-se uma planilha de Revisão Interacional que pode ser adaptada e utilizada na escola, além de refletir acerca do processo de produção e de reescrita textual.

Palavras-chave: Linguística Aplicada; Ensino Médio; Produção e Reescrita Textual.

\section{ABSTRACT}

This paper is about the process of text's production and rewriting in High School. The work's aim is deal with studies about the linguistic knowledge construction in a processual perspective (GERALDI, 1997), from the optic of Dialogical Discourse Analysis and Applicated Linguistics. As a methodologic basis, the research has theoretic-practical nature, with qualitative-interpretative approach and explicative purposes. The technical procedures corresponds to the bibliographic revision research, case study and action-research. The production of registers happens through the bibliographic indirect documentation and the direct one in the documental description. The main method of analysis and data interpretation is the dialectic one, having as secondary subside, the monograpic, comparative ahd historical technic procedures. As results, it is proposed an Interactional Revision spreadsheet which can be adapted and used in the school, besides refleting about the textual production and rewriting process.

Keywords: Applicated Linguistics; High School; Textual Production and Rewriting Process.

\section{Introdução}

A partir de construtos teóricos bakhtinianos em relação à compreensão do texto como forma de interação, pauta-se, neste estudo, na concepção dialógica e interacional de linguagem, considerando o sujeito e as diversas situações de enunciação (Bakhtin/Volochínov, 2003 [1929]; Bakhtin, 2009[1979]). Propõe-se, dessa maneira, o trabalho com a produção e a reescrita textual na Rede Básica de Ensino, a fim de refletir sobre caminhos para a efetivação de uma prática didático-pedagógica concernente aos letramentos necessários ao contexto escolar em foco. 
Nesse prisma, o estudo encaminha-se pelos pressupostos metodológicos da transdisciplinaridade ao fazer pesquisa em Linguística Aplicada, ${ }^{1}$ uma vez que se propõe a observação de uma realidade de ensino, visando à reflexão sobre as dinâmicas geradas na aula de produção e de reescrita textual com estudantes do $2^{\circ}$ ano do Ensino Médio. ${ }^{2}$ Justifica-se essa delimitação, uma vez que se entende "[...] o conhecimento [acontecer] pela aproximação do sujeito com o problema em sucessivas aproximações e recusas.” (Lucena; Sarava; Almeida, 2016, p. 10).

Nesse viés, o trabalho tem como objetivo, a partir dos pressupostos teóricos da escrita como processo (Geraldi, 1997), sob a óptica da Análise Dialógica do Discurso - $\mathrm{ADD}^{3}$ e da Linguística Aplicada- LA ${ }^{4}$ responder

1 A transdisciplinaridade, ao se fazer pesquisa em Linguística Aplicada, tem-se mostrado um caminho possível no trabalho de estudiosos dessa área do saber (Moita Lopes, 2006; Signorini; Cavalcanti, 2004), por se defender um hibridismo teórico-metodológico na pesquisa qualitativo-interpretativista que proponha a problematização, a reflexão crítica, eivada pela Ética e centrada nas necessidades das práticas sociais de uma sociedade democrática de direito. Para essa concepção, a língua(gem) "[...] manifesta-se como um instrumento dialógico nas relações em sociedade: expressa o pensamento do sujeito/ indivíduo social, medeia conhecimentos e atua sobre o outro e o mundo que o cerca. Trata-se de um sistema semiótico, que flui continuamente, constituído pela e na produção social, histórica, cultural e ideológica em uma dada comunidade de prática linguística. A linguagem, com efeito, responde a duas faces: a) uma formal, em que prevalece o sistema linguístico, de significação apreendida, de função referencial-informativa, com predomínio da acepção dicionarizada das palavras e das expressões, atuando como signos neutros; b) uma discursiva, em que se evidencia um sistema translinguístico, que transcende a significação e serve à produção de sentido, com caráter social e histórico de intercâmbio comunicativo, a partir das manifestações de intencionalidade do sujeito, inseridas nos processos ideológicos do discurso, em que as palavras e as expressões equivalem a signos sociais. (Kraemer; Lunardelli; Costa-Hübes, 2020, p. 64).

2 De ora em diante, utilizar-se-á a sigla EM para a referência ao Ensino Médio.

3 A ADD é uma teoria do Círculo de Bakhtin. Segundo Costa-Hübes, o "Círculo de Bakhtin correspondia a um grupo multidisciplinar de intelectuais russos que se reuniam regularmente entre 1919 e 1929, preocupados com as formas de estudar linguagem, literatura e arte. Incluía o linguista Valentin Volochinov (1895-1936), o teórico literário Pavel Medvedev (1891-1938), Mikhail Bakhtin (1895-1975) dentre outros.” (Costa-Hübes, 2014, p. 20). De ora em diante, utilizaremos a sigla ADD para a referência à Análise Dialógica do Discurso.

4 De ora em diante, utilizar-se-á a sigla LA para a referência à Linguística Aplicada.

Confluência. Rio de Janeiro: Liceu Literário Português, n. 61, p. 434-462, jul.-dez. 2021 
à indagação de pesquisa do estudo: em que medida se podem efetivar os processos de escrita e de reescrita em contexto de EM? Elencam-se, como objetivos específicos:

a) Estudar o construto teórico da ADD no que tange aos elementos constitutivos dos textos-enunciados de gêneros discursivos;

b) Pesquisar como se efetiva o processo de escrita e de reescrita sob a óptica da LA;

c) Investigar, por meio de observação descritivo-analítica, o trabalho com a produção e a reescrita do texto em uma turma do $2^{\circ}$ Ano do EM.

Para isso, orientados teoricamente pelos pressupostos da ADD, recorrese ao pensamento linguístico do Círculo de Bakhtin (Volochínov/Bakhtin, 1926; Bakhtin/Volochínov, 2003[1929]; Bakhtin, 2009[1979]), com foco na produção e reescrita textual (Geraldi, 1997; Menegassi, 2010; 2016; Costa-Hübes, 2012).

Para a geração de dados, a pesquisa teórico-empírica, de cunho qualitativo-interpretativista, com fins explicativos, pauta-se em uma prática de ensino no viés da pesquisa-ação, em que uma das pesquisadoras assume tanto o papel de professora como de observadora, partícipe na ação e na observação. Os dados são gerados por documentação indireta (pesquisa bibliográfica) e direta intensiva (pesquisa-ação). O método principal de análise e de interpretação é o dialético, centrando-se na reflexão acerca do processo do fenômeno em curso, e o método de procedimento é o histórico (construto teórico), o comparativo (teoria versus prática) e o monográfico (estudo de caso).

O desenvolvimento do artigo encontra-se organizado da seguinte forma: primeiro, expõe-se a compreensão de texto como forma de interação, a partir do processo de produção e de reescrita textual; na sequência, descreve-se o processo de geração dos registros e da caracterização dos sujeitos participantes da pesquisa; após isso, apontam-se as reflexões acerca do processo de produção e de reescrita textual; e, por fim, os resultados alcançados por meio da pesquisa. 


\section{O texto como forma de interação: produção e reescrita textual}

Ao compreendemos o texto como forma de interação, realizamos o processo de produção e de reescrita de textos, adotando a escrita como processo (Geraldi, 1997). Desse modo, segundo Geraldi, como mediadores do conhecimento, os professores devem propor um comando para produção, possibilitando ao estudante: a) o que dizer; b) para quem dizer o que se tem a dizer; c) estratégias para dizer o que se tem a dizer (Geraldi, 1997). Conforme Menegassi, é preciso uma finalidade definida, isto é, o intuito, o porquê do dizer (Menegassi, 2010; 2016). Além disso, é necessário atentar para a interlocução que pode ser: a) real, quando o outro se faz presente no momento da escrita; b) virtual, quando se projeta o outro na produção; c) superior, quando se leva em consideração o ambiente institucional na interlocução:

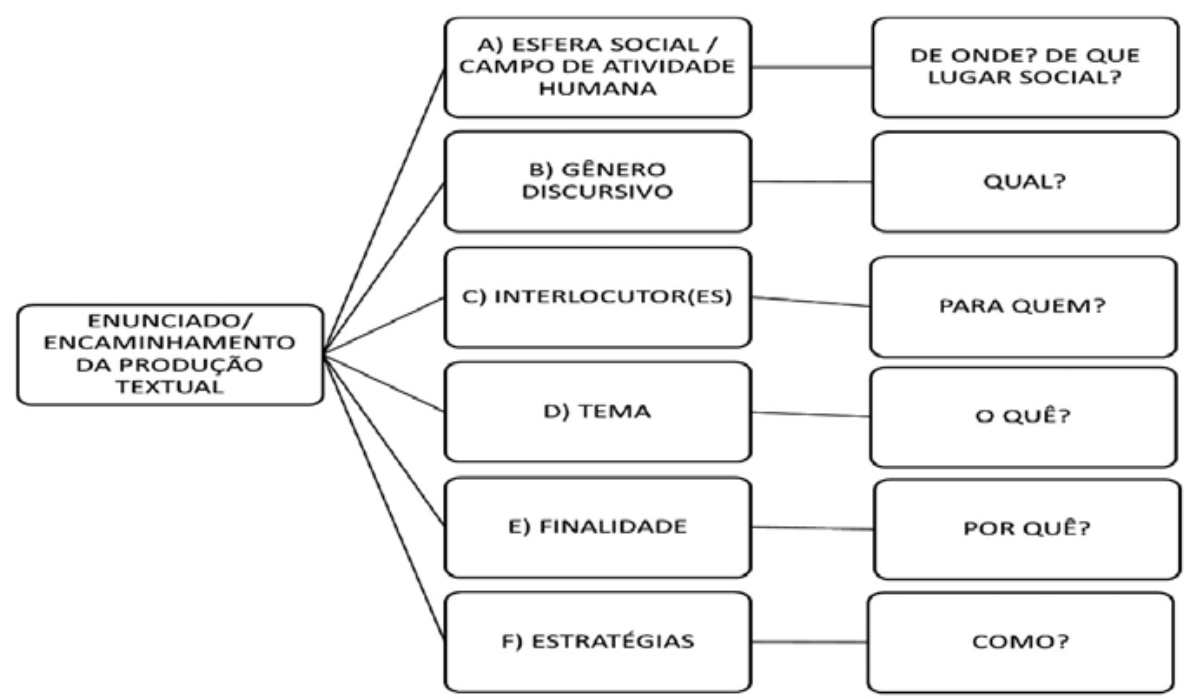

Figura 1. Elementos que encaminham uma proposta de produção de texto para a interação. Fonte: Costa-Hübes (2012, p. 11).

Confluência. Rio de Janeiro: Liceu Literário Português, n. 61, p. 434-462, jul.-dez. 2021 
Também, é importante compreender que o estudo do gênero discursivo deve ser construído como um trabalho prévio, a partir do qual se preparam reflexões acerca de seu contexto mediato, com seus elementos constitutivos (referencialidade, expressividade e endereçabilidade), bem como imediato, com seus elementos orgânicos (projeto enunciativo, exauribilidade, conteúdo temático, construção composicional e estilo), consubstanciado em suas diversas situações de uso nos diferentes campos de atividade humana (Sobral; Giacomelli, 2016; Bakhtin/Volochínov, 2003 [1929]).

Outro aspecto primordial é o de que a circulação social estabelecida, na produção de textos, sobressaia o ambiente escolar, evidenciando sua função social e comunicativa. Ainda, para a efetivação do processo, é preciso definir um suporte textual, no qual o texto possa circular, como uma folha de papel ou até mesmo um site de internet. Para finalizar, é indispensável evidenciar o posicionamento social do autor. Todos esses elementos são essenciais para que o estudante tenha condições de realizar sua produção escrita.

Após o momento da escrita, que é o ato de escrever efetivamente, a revisão acontece, podendo ser realizada por um colega, pelo próprio aluno ou pelo professor. A partir das correções e das sugestões realizadas em seu texto, o estudante o reescreve, adequando-o à situação de enunciação.

Sendo assim, todo o processo discutido caracteriza a prática de escrita como um processo que corresponde à concepção interacional de linguagem (Perfeito, 2010), proposta pelas Diretrizes Estaduais, doravante DCE de Língua Portuguesa (Paraná, 2008), as quais defendem a constituição do sujeito pelas interações estabelecidas com outro(s) no ambiente social em que vive. Nessa perspectiva, o professor torna-se mediador e coprodutor de sentidos e não simplesmente avaliador, primando pelo trabalho com a produção de textos em que, de fato, sejam aprimoradas as capacidades linguístico-discursivas de seus estudantes.

Ao partir de uma situação real de ensino, na qual o professor realiza a análise reflexiva do texto de seu aluno, promovendo a interação, destacamse, neste artigo, as três maneiras geralmente usadas pelos docentes, conforme 
Serafini, para estabelecer a revisão das produções escolares: a indicativa, a resolutiva e a classificatória (Serafini, 1989).

$\mathrm{Na}$ indicativa, o docente apenas indica os pontos positivos e os pontos de melhoria para o estudante sem o auxiliar, ficando a cargo de o aluno descobrir em quais aspectos deve aprimorar seu texto. A forma resolutiva é apenas o ato de apontar aspecto de melhoria do texto para o estudante, acontecendo, geralmente, a demarcação no próprio texto ou em sua margem, na qual o professor apenas grifa ou sinaliza, por exemplo, a palavra e a corrige para o educando, fornecendo-lhe a resposta para apenas passar a limpo (Serafini, 1989).

Em relação à maneira classificatória, o professor classifica os erros ou inadequações, podendo acontecer em forma de tabela ou no próprio texto, por numerações ou abreviações combinadas previamente com os estudantes. Ruiz, entretanto, acrescenta a revisão textual-interativa que corresponde a comentários que podem estar posicionados ao final do texto, como um bilhete, ou na margem do texto, focalizando aspectos relacionados ao conteúdo global da escrita. Dessa forma, propicia ao estudante a reflexão sobre sua prática, adequando sua produção à situação de uso (Ruiz, 2015 [2010]).

Simioni apresenta uma reelaboração do tipo de correção classificatória, nomeando-a classificatória interativa, pois, para além da classificação e do reagrupamento dos possíveis problemas do texto, o professor estabelece o diálogo com o estudante, auxiliando-o a refletir sobre suas escolhas linguístico-discursivas (Simoni, 2012). Desse modo, conforme a autora, essa correção focaliza a utilização de códigos categorizadores para apontar no texto as inadequações e, também, no “[...] diálogo individualizado com o aluno, explicando os sinais e fazendo-o refletir sobre sua escrita e sobre o que seria necessário alterar para adequá-la à situação de comunicação." (Simoni, 2012, p. 103).

Além disso, consideraram-se os aspectos linguístico-discursivos realizados pelo discente em sua segunda versão, os quais podem ser de: 
a) Adição, ou acréscimo: [...] acréscimo de um elemento gráfico, acento, sinal de pontuação, grafema [...] mas também do acréscimo de uma palavra, de um sintagma, de uma ou de várias frases.

b) Supressão: supressão sem substituição do segmento suprimido. Ela pode ser aplicada sobre unidades diversas, acento, grafemas, sílabas, palavras sintagmáticas, uma ou diversas frases.

c) Substituição: supressão, seguida de substituição por um termo novo. Ela se aplica sobre um grafema, uma palavra, um sintagma, ou sobre conjuntos generalizados.

d) Deslocamento: permutação de elementos, que acaba por modificar sua ordem no processo de encadeamento. (FABRE, 1986, p. 69).

Tais aspectos realizados pelo discente estão estritamente ligados à revisão empreendida pela professora, sendo uma atitude responsiva de manifestação da contra palavra ao apontamento do docente. A contra palavra é um conceito do dialogismo que, para Bakhtin/Volochínov (2003[1929]), condiz à apropriação da voz/palavra do outro pelo sujeito que a ressignifica a partir de suas próprias experiências.

Nessa perspectiva, a professora-pesquisadora, partícipe da pesquisaação, realiza predominantemente a revisão que se aproxima do que a teoria categoriza como correção classificatória interativa. Contudo, para além do uso de uma planilha classificatória, ela acompanha todo o processo de produção e de reescrita textual em sala de aula, apontando os pontos positivos, primeiramente, bem como os pontos de melhoria, explicando as inadequações e as alterações necessárias para o aprimoramento do texto, ao estabelecer uma relação dialógica entre professor coautor e aluno produtor do enunciado. Por isso se categoriza essa revisão como interacional, uma vez que trabalha dialogicamente a produção do enunciado, haja vista que medeia presencialmente o processo de revisão e de reescrita dos textos, ressaltando aspectos da forma e do conteúdo das produções.

Logo, apesar de a professora em questão realizar, em parte das etapas da escrita e da reescrita, uma revisão interacional, consideram-se todos os tipos de estratégias descritas pertinentes em relação ao processo de 
produção do texto, podendo ser utilizadas simultaneamente ou isoladamente, dependendo da intencionalidade docente e da atividade. Na sequência, tratase da geração dos registros realizados pelas pesquisadoras, a fim de provocar a reflexão acerca de todo o processo de produção e de reescrita dos textos, objetos de análise deste estudo.

\section{A descrição da geração de registros e os sujeitos participantes da pesquisa}

Convém ressaltar que o presente artigo corresponde a um estudo em Ciências Humanas, pautado, teoricamente, no viés bakhtiniano, em se tratando de concepção de língua(gem). ${ }^{5}$ Tal investigação também se ancora na LA, em sua vertente ligada ao ensino e à aprendizagem de Língua Portuguesa no EM. Enfatiza-se a orientação teórica-empírica da pesquisa, uma vez que se estabelece um cotejo entre teoria e prática, com cunho qualitativointerpretativista, cujo foco é analisar e interpretar os dados subjetivamente, estudando as particularidades do fenômeno investigado a partir de um recorte no microcosmo social, neste caso, a sala de aula, considerada um ambiente propício a esse tipo de pesquisa (Bortoni-Ricardo, 2008).

A pesquisa-ação é um dos procedimentos técnicos escolhidos, sendo uma das pesquisadoras, como já mencionado, partícipe na ação e na observação, junto aos estudantes, visto que as reflexões empíricas partem do contexto da sala de aula. Considera-se que esse tipo de posicionamento é relevante e demanda muita atenção processual, pois a professora pesquisadora procura analisar o trabalho que desenvolve como outra de si mesma (Bakhtin/Volochínov, 2003 [1929]), procurando, com efeito, perceber os pontos cegos (Erickson, 2001, p.13) não observados do lugar de professor, no cotidiano das aulas.

5 Nos escritos do Círculo de Bakhtin não há distinção entre língua e linguagem. Por isso, emprega-se, neste artigo, o termo língua(gem), 
Essa técnica procedimental de geração de dados, é elegida, para potencializar o entrelaçamento do estudo teórico ao empírico. Tal viés, ao mesmo tempo, investiga e produz conhecimentos sobre a realidade estudada, como também realiza um processo educativo para o enfrentamento dessa realidade (Reis, 2009). O seu ponto de partida é o de articular a produção de conhecimentos, com vistas à conscientização dos sujeitos e à proposição de soluções aos problemas sociais. A pesquisa-ação educacional é essencialmente uma estratégia para o desenvolvimento de professores e de pesquisadores, de modo que eles possam utilizar suas investigações para aprimorar o ensino e, em decorrência, o aprendizado de seus alunos (Tripp, 2005).

Utiliza-se, ainda, como ferramenta para a geração dos dados, de acordo com o mencionado na introdução deste texto, a documentação indireta (pesquisa bibliográfica) e a direta intensiva (pesquisa-ação). $\mathrm{O}$ método dialético subsidia a análise e a interpretação dos dados, em virtude de refletir sobre o fenômeno em curso, tendo, como recurso procedimental, o método histórico (construto teórico), o comparativo (teoria versus prática) e o monográfico (estudo de caso).

As informações analisadas, neste trabalho, articulam-se por meio de aulas de Produção Textual, ministradas em uma turma de $2^{\circ}$ Ano do EM de uma escola particular, situada no Oeste paranaense. Essa aula é parte constituinte de uma sequência de atividades didáticas desenvolvidas pela professora em torno do gênero Redação do Enem, no primeiro semestre de 2019.

Em relação aos sujeitos envolvidos na produção empírica das informações, a professora que medeia às atividades tem 10 anos de experiência docente em Rede Privada de Ensino. A turma, foco da pesquisação, é constituída por 22 estudantes de quatro cidades diferentes, sendo elas Guaraniaçu, Campo Bonito, Ibema e Catanduvas. A faixa etária dos discentes varia entre 15 e 16 anos.

Diante dos objetivos estabelecidos neste estudo e pretendendo responder aos questionamentos norteadores do trabalho, a seguir, tratam-se das atividades didático-pedagógicas: a proposta de produção textual e a revisão interacional, 
a partir do método sociológico de análise de gênero, de acordo com o que preconiza a ADD e as teorias acerca da produção e da reescrita textual.

\subsection{Proposta de Produção Textual e de Revisão Interacional}

A partir da teoria adotada para a produção da Redação do Enem, a professora planeja o trabalho e, ao propor a introdução da atividade para os alunos, (re)apresenta qual é o propósito interdisciplinar do ensino de língua(gem), em que se integram quatro componentes curriculares: Gramática, Literatura, Interpretação Textual e Produção Textualintenção, por parte da docente, de estabelecer a integração entre os conhecimentos atinentes ao estudo linguístico, de forma holística, uma vez que ministra as quatro frentes.

A Produção Textual equivale a um componente na composição da avaliação somativa, mas não em relação à carga horária, sendo integrada ao planejamento das outras três frentes. As orientações iniciais aos alunos, para apresentar a atividade, são realizadas de forma dialogada e interacional, com o intuito de estabelecer o saber partilhado entre docente e discente sobre o conteúdo a ser desenvolvido. Para sintetizar as informações que são discutidas, apresenta-se o Quadro 1:

Quadro 1. Proposta de Produção Textual - Orientações Iniciais.

\begin{tabular}{|l|c|}
\hline \multicolumn{2}{|c|}{ PROPOSTA DE PRODUÇÃO TEXTUAL } \\
\hline \multicolumn{2}{|c|}{ ORIENTAÇÕES INICIAIS } \\
\hline \multicolumn{1}{|c|}{ Condições de Produção } \\
\hline \multicolumn{1}{|c|}{ Conteúdo Programático da Atividade } \\
\hline $\begin{array}{l}|c| \\
\text { - Linguagens, Códigos e suas Tecnologias } \\
\text { - Interpretação Textual }\end{array}$ \\
\hline
\end{tabular}




\begin{tabular}{|c|c|}
\hline \multicolumn{2}{|c|}{ Objetivos da Atividade } \\
\hline Objetivo Geral & Objetivos Específicos \\
\hline $\begin{array}{l}\text { Produzir uma Redação do Enem a } \\
\text { partir do estudo do tema Leitura, } \\
\text { pensamento crítico e autonomia. }\end{array}$ & $\begin{array}{l}\text { - Observar o conteúdo temático, a construção } \\
\text { composicional e o estilo de linguagem, por } \\
\text { meio da categoria retórica dissertativo- } \\
\text { argumentativa do gênero discursivo Redação } \\
\text { do Enem; } \\
\text { - Refletir sobre a apropriação da habilidade } \\
\text { de argumentação dos alunos, por meio das } \\
\text { atividades prévias; } \\
\text { Diagnosticar o desenvolvimento das } \\
\text { habilidades de escrita e das capacidades } \\
\text { linguístico-discursivas dos estudantes. }\end{array}$ \\
\hline \multicolumn{2}{|c|}{ Carga Horária e Componentes Curriculares } \\
\hline \multicolumn{2}{|c|}{$\begin{array}{l}\text { Por se tratar de cinco aulas semanais ao estudo de Língua Portuguesa, sendo duas horas/ } \\
\text { aula dedicadas ao Componente Curricular de Literatura, duas para Gramática e uma para } \\
\text { Produção Textual, a proposta de atividade compreende o período destinado à Produção } \\
\text { Textual, utilizando três aulas (uma por semana), sendo que, na última etapa, a finalização } \\
\text { resulta na produção do texto do gênero Redação do Enem, cuja categoria retórica é a } \\
\text { dissertação-argumentativa. }\end{array}$} \\
\hline \multicolumn{2}{|c|}{ Métodos Procedimentais } \\
\hline $\begin{array}{l}\text { O método que norteia a leitura e } \\
\text { contexto situacional da Redação d } \\
\text { de produção do gênero, com a an } \\
\text { situacionalidade, expressividade) e } \\
\text { temático, composicional e de estil }\end{array}$ & $\begin{array}{l}\text { ução textual é o sociológico, em que se parte do } \\
\text { m, propiciando a reflexão acerca da prática social } \\
\text { de seus elementos constitutivos (referencialidade, } \\
\text { icos (projeto enunciativo: aceitabilidade, conteúdo } \\
\text { lém disso, há o enfoque também no processo de }\end{array}$ \\
\hline
\end{tabular}




\section{Reflexão Analítica acerca da Produção Textual}

- A reflexão analítica acerca da produção textual tem como objetivo principal diagnosticar, de maneira formativa, a apropriação e o desenvolvimento do estudante no processo de produção e de reescrita do texto, a fim de uma devolutiva para a docente acerca da metodologia adotada na atividade proposta.

- Sugere-se que os apontamentos anotados pela professora no processo de revisão devem ser observados com atenção, para possibilitar a progressão dos pontos favoráveis e de melhoria do texto;

- Enfatiza-se a preocupação em cumprir com o acordado sobre os prazos de entrega e de devolutiva das produções, no intuito de que o processo desenvolva-se de forma a otimizar os resultados.

- As produções serão valoradas conforme o convencionado nas disciplinas em que se integra. $^{6}$

Após o esclarecimento acerca das orientações iniciais, em que a professora apresenta os objetivos da aula e as etapas que serão realizadas durante o processo de produção textual, a docente, juntamente com os alunos, estuda um texto produzido por um estudante em situação de Enem que atende à proposta do gênero no ano de 2014, como forma ilustrativa para os passos seguintes. No material didático, fazem a leitura e refletem sobre as competências avaliadas pelo Enem em cotejo com a redação analisada.

Em seguida, a professora propõe aos alunos a leitura de uma coletânea de textos acerca do tema Leitura, pensamento crítico e autonomia,${ }^{7}$ começando

6 A produção escrita convencionalmente tem um valor de 8,0 pontos de um total de 10,0. Esse valor consta no Projeto Político Pedagógico da Escola: 8,0 pontos de atividades avaliativas e 2,0 pontos distribuídos em trabalhos e atividades afins. Os estudos sobre Produção Textual inserem-se nos diferentes componentes, mas compõem uma nota distinta. Ao final do trimestre, são somadas as quatro médias, resultando em uma única nota de Português.

7 A proposta de produção textual é selecionada no material apostilado da turma (Pereira, 2018).

Confluência. Rio de Janeiro: Liceu Literário Português, n. 61, p. 434-462, jul.-dez. 2021 
com a pré-leitura do título, a fim de que os estudantes criem hipóteses sobre o conteúdo as quais serão cotejadas posteriormente:

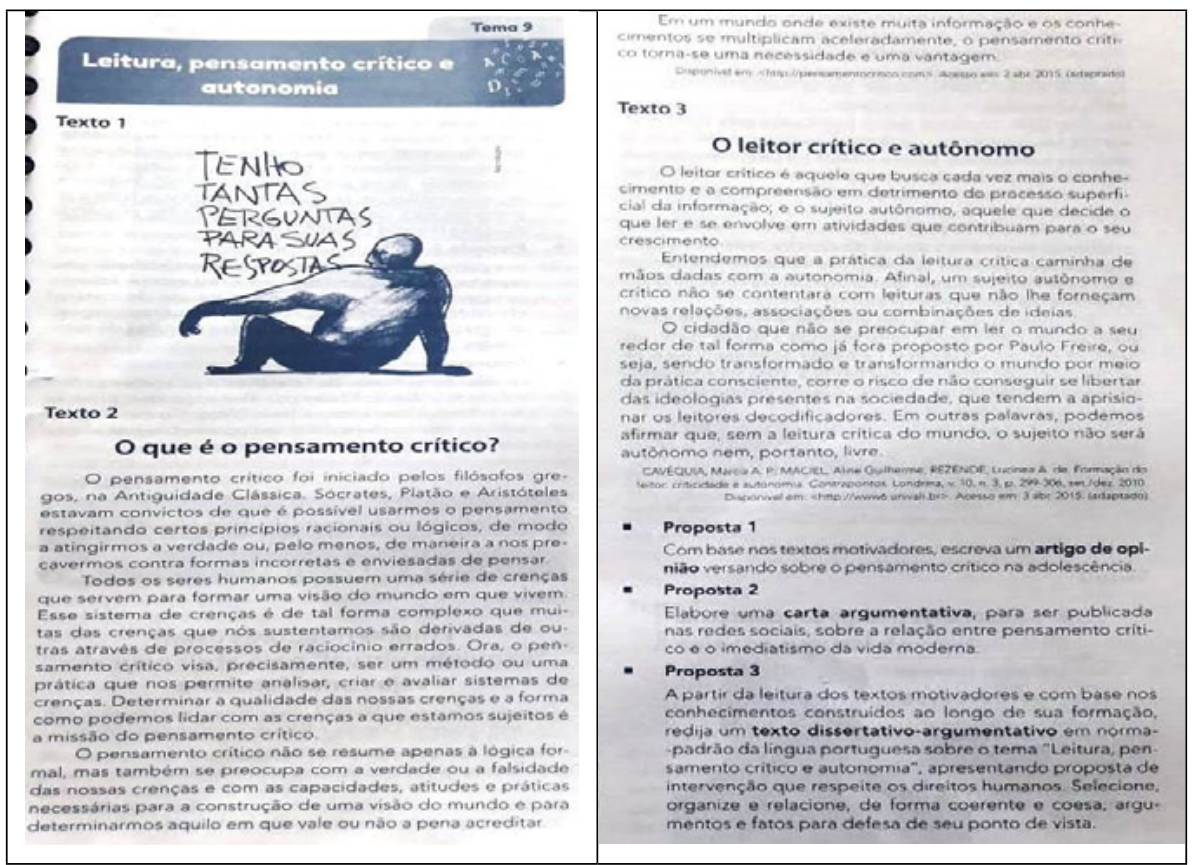

Figura 2. Textos acerca da temática Leitura, pensamento crítico e autonomia Fonte: Pereira (2018, p. 17).

Depois da leitura - primeiro, individual e silenciosa, em seguida, em conjunto e oral -, a docente inicia o diálogo com os alunos no tocante à temática, comparando as hipóteses elencadas na etapa da pré-leitura, com a compreensão que os estudantes apresentam posteriormente à leitura propriamente dita dos textos. Logo, elenca com os alunos a delimitação e o enfoque temático presentes na coletânea (Menegassi; Zanini, 1997), estabelecendo um diálogo acerca desse mapeamento e dos principais argumentos que poderão subsidiar a produção textual dos alunos. Por meio dessa discussão, apresenta o seguinte comando de produção (Figura 2):

Confluência. Rio de Janeiro: Liceu Literário Português, n. 61, p. 434-462, jul.-dez. 2021 


\begin{abstract}
A partir da leitura dos textos motivadores e com base nos conhecimentos construídos ao longo de sua formação, redija um texto dissertativoargumentativo em norma padrão da língua portuguesa sobre o tema "Leitura, pensamento crítico e autonomia", apresentando proposta de intervenção que respeite os direitos humanos. Selecione, organize e relacione, de forma coerente e coesa, argumentos e fatos para a defesa de seu ponto de vista. (Pereira, 2018, p. 17).
\end{abstract}

De acordo com Triviños, para que os resultados da pesquisa possam ser interpretados, deve-se considerar o todo, isto é, o objeto de investigação deve ser tomado no seu contexto imediato de produção (Triviños, 1987). Assim, antes de iniciar o processo de escrita, a professora medeia à produção de um plano de texto no quadro, guiando-se pelo método sociológico de estudo de gêneros discursivos, com foco nas regularidades/estabilidades de textos-enunciados do Enem:

Quadro 2. Elementos Constitutivos e Orgânicos do Gênero Discursivo

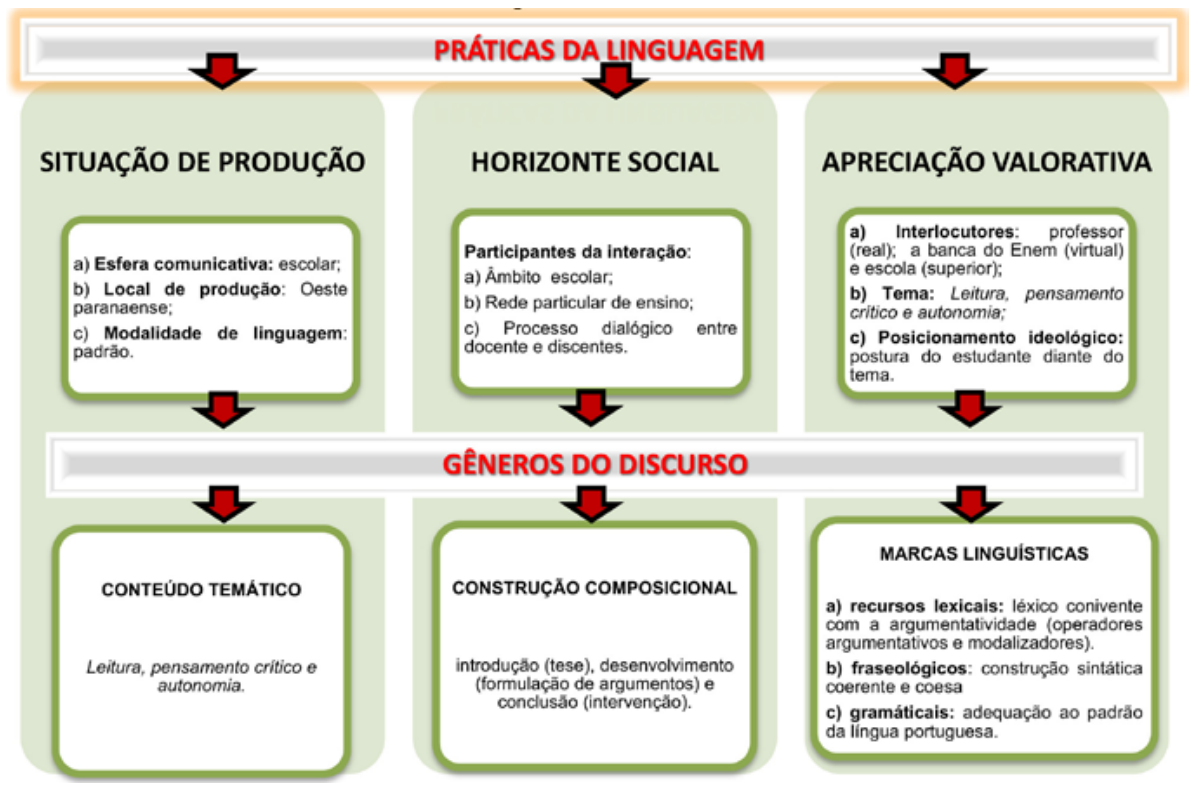

Confluência. Rio de Janeiro: Liceu Literário Português, n. 61, p. 434-462, jul.-dez. 2021 
Posteriormente, debatem sobre o planejamento da produção escrita, abarcando o conteúdo temático Leitura, pensamento crítico e autonomia. Desse modo, é propiciado o conhecimento da temática, a fim de que o estudante tenha o que dizer. A partir da leitura dos textos motivadores sobre o tema, os alunos são convidados a elencar, em seus cadernos, de oito a dez argumentos relacionados à proposta. Em seguida, a professora evidencia exemplos possíveis de estruturar composicionalmente o gênero discursivo Redação do Enem, levando exemplos de textos desse gênero que circulam socialmente, para os discentes se familiarizarem, tratando de sua composição: introdução (tese), desenvolvimento (formulação de argumentos) e conclusão (intervenção).

No material didático, examinam os tipos de argumentos (citação, raciocínio lógico, evidências, etc.), a fỉm de propiciar as condições necessárias para a produção textual. Logo, a professora, com o auxílio dos estudantes, faz um planejamento no quadro, coletivamente, sobre o tema proposto, como um exercício prévio, ilustrativo, a fim de materializar os passos metodológicos da produção textual.

A partir disso, solicita aos estudantes que façam um esboço estrutural próprio e individual do texto, contendo uma tese já explícita na introdução, até três argumentos que serão os tópicos frasais dispostos nos parágrafos do desenvolvimento e a proposta de intervenção na conclusão (de acordo com o solicitado pelo comando de produção), sendo que, nesta, deve haver a peroração. ${ }^{8}$

Além disso, a professora orienta acerca do estilo de linguagem formal que precisa ser utilizado, identificando com eles o uso de estratégias que possam favorecê-los no momento da escrita. Por fim, apresenta a Planilha

8 Em retórica clássica, a peroração encontra-se na conclusão do texto, tendo o propósito de lembrar à audiência os pontos principais do discurso e influenciar suas emoções, persuadindo-a a aderir à tese do produtor do texto. Segundo Reboul, equivale ao momento por excelência em que a afetividade se une à argumentação e, por essa razão, conclama à ação (Reboul, 2004, p. 60). 


\section{de Revisão Interacional - PRI, ${ }^{9}$ que pode norteá-los no que tange ao que se espera em sua produção e de como as revisões acontecerão nesse processo.}

Quadro 3. Planilha de Revisão Interacional - PRI

\begin{tabular}{|c|c|c|}
\hline \multicolumn{3}{|c|}{ PLANILHA DE REVISÃO INTERACIONAL } \\
\hline \multirow{7}{*}{ 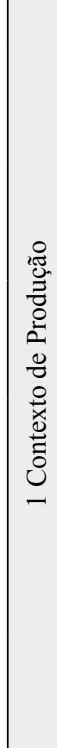 } & 1.1 Situação de produção, horizonte social e de expectativa: & \\
\hline & $\begin{array}{l}\text { 1.1.1 Trata-se de um do gênero solicitado pelo comando de } \\
\text { produção? }\end{array}$ & $\begin{array}{l}\text { Sim ( ) } \\
\text { Não ( ) } \\
\text { Parcial ( ) }\end{array}$ \\
\hline & $\begin{array}{l}\text { 1.1.2 Atende-se, no texto, à necessidade de interação estabelecida } \\
\text { (esfera comunicativa) de acordo com o contexto de produção? (A } \\
\text { quem se dirige, quando e onde? Lugar social de interação). }\end{array}$ & $\begin{array}{l}\text { Sim ( ) } \\
\text { Não ( ) } \\
\text { Parcial ( ) }\end{array}$ \\
\hline & $\begin{array}{l}\text { 1.1.3 Apresenta-se, no texto, a modalidade de linguagem adequada } \\
\text { para o contexto de produção solicitado? }\end{array}$ & $\begin{array}{l}\text { Sim }(\text { ) } \\
\text { Não ( ) } \\
\text { Parcial ( ) }\end{array}$ \\
\hline & $\begin{array}{l}\text { 1.1.4 Identifica-se, no texto, (implícita ou explicitamente) os } \\
\text { interlocutores imediatos/preferenciais/reais, secundários/virtuais } \\
\text { e em potencial/superiores? }\end{array}$ & $\begin{array}{l}\text { Sim }(\text { ) } \\
\text { Não ( ) } \\
\text { Parcial ( ) }\end{array}$ \\
\hline & $\begin{array}{l}\text { 1.1.5 Reconhece-se, no texto, de forma global e genérica, o tema } \\
\text { proposto pelo comando de produção? }\end{array}$ & $\begin{array}{l}\text { Sim ( ) } \\
\text { Não ( ) } \\
\text { Parcial ( ) }\end{array}$ \\
\hline & $\begin{array}{l}\text { 1.1.6 Distingue-se, ao longo do texto, o posicionamento } \\
\text { ideológico defendido pelo produtor do texto? }\end{array}$ & $\begin{array}{l}\text { Sim ( ) } \\
\text { Não ( ) } \\
\text { Parcial ( ) }\end{array}$ \\
\hline
\end{tabular}

continua

9 A denominação Planilha de Revisão Interacional, doravante PRI, espelha-se na concepção interacional de linguagem e nas teorias sobre a produção textual, de acordo com a ADD. Opta-se por essa terminologia, uma vez que a produção e a reescrita de texto acontecem em diferentes âmbitos de constituição do gênero discursivo, seja no plano do conteúdo temático, no da estrutura composicional ou no do estilo de linguagem (Sobral, 2019). Justifica-se o uso da Planilha de Revisão Interacional, em função do que assevera Serafini, ao afirmar que é "[...] fundamental fornecer aos alunos uma planilha de análise [...]" para nortear o entendimento do estudante sobre o processo de escrita e de reescrita (Serafini, 1989, p. 119). Esclarece que eles "[...] têm [de] perceber com clareza que a [revisão] deve contribuir para o aperfeiçoamento do texto em alguns de seus aspectos específicos, sobre os quais o autor possa trabalhar [...]" (Serafini, 1989, p. 119). Dessa forma, é preciso que o docente determine orientações para que o aluno tenha a possibilidade de revisar sua produção escrita em busca de pontos de melhoria. Tais encaminhamentos constituem a análise do professor acerca do processo de produção textual, propiciando o diálogo com o aluno, em um processo de alteridade entre autor/texto/leitor.

Confluência. Rio de Janeiro: Liceu Literário Português, n. 61, p. 434-462, jul.-dez. 2021 


\begin{tabular}{|c|c|c|}
\hline \multicolumn{3}{|c|}{ PLANILHA DE REVISÃO INTERACIONAL } \\
\hline \multirow{17}{*}{ 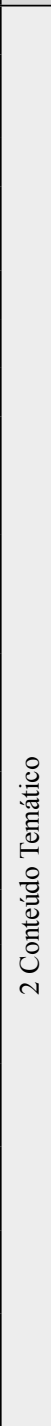 } & 2.1 A produção apresenta: & \\
\hline & $\begin{array}{l}\text { 2.1.1 Título Impertinente: fuga ao tema ou repete o título do texto } \\
\text { de apoio, com algum erro ou inadequação. }\end{array}$ & \\
\hline & 2.1.2 Título paráfrase: parafraseia o título do texto de apoio. & \\
\hline & $\begin{array}{l}\text { 2.1.3 Título pertinente: apresenta-se articulado ao texto ou como } \\
\text { síntese dele. }\end{array}$ & \\
\hline & 2.1.4 Título criativo: é um convite sedutor à leitura. & \\
\hline & 2.2 A proposição temática da produção apresenta: & \\
\hline & 2.2.1 Fuga ao tema proposto. & \\
\hline & $\begin{array}{l}\text { 2.2.2 Leitura tangencial: toca no assunto, mas não o tematiza; } \\
\text { apresenta divagações, fragmentos dos textos de apoio ou, ainda, } \\
\text { trabalha apenas o assunto proposto. }\end{array}$ & \\
\hline & $\begin{array}{l}\text { 2.2.3 Leitura superficial: apresenta elementos que apontam para o } \\
\text { desenvolvimento do tema, ou seja, para o enfoque temático, mas } \\
\text { não vai além das informações dos textos de apoio. }\end{array}$ & \\
\hline & $\begin{array}{l}\text { 2.2.4 Leitura adequada: desenvolve o tema completo; acrescenta } \\
\text { informação nova, mas não apresenta tese ou a expõe incompleta } \\
\text { ou, ainda, fundamenta-a no senso comum. }\end{array}$ & \\
\hline & $\begin{array}{l}\text { 2.2.5 Leitura complexa: desenvolve o tema, com enfoque temático } \\
\text { e contempla informação nova, retomando-a com fins a persuadir } \\
\text { o leitor. }\end{array}$ & \\
\hline & 2.3 A argumentatividade da produção apresenta: & \\
\hline & $\begin{array}{l}\text { 2.3.1 Problemas gravíssimos: sem expansão textual, com } \\
\text { exemplos inadequados ou divagação, mas não foge totalmente ao } \\
\text { tema. }\end{array}$ & \\
\hline & $\begin{array}{l}\text { 2.3.2 Problemas: pouca argumentação; problemas na progressão, } \\
\text { com algumas contradições internas e externas. }\end{array}$ & \\
\hline & $\begin{array}{l}\text { 2.3.3 Boa: apresenta uma tese, mas a argumentação não apresenta } \\
\text { muita elaboração. }\end{array}$ & \\
\hline & $\begin{array}{l}\text { 2.3.4 Muito boa: apresenta tese, argumentação que extrapola o } \\
\text { texto de apoio, mas faltam marcas de persuasão do leitor ao final. }\end{array}$ & \\
\hline & $\begin{array}{l}\text { 2.3.5 Ótima: apresenta uma tese; argumentação extrapola o texto } \\
\text { de apoio; conclusão com intervenção e evidências de convencer } \\
\text { o leitor. }\end{array}$ & \\
\hline
\end{tabular}




\begin{tabular}{|c|c|c|}
\hline \multicolumn{3}{|c|}{ PLANILHA DE REVISÃO INTERACIONAL } \\
\hline \multirow{5}{*}{ 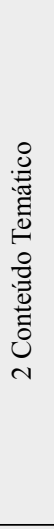 } & \multicolumn{2}{|l|}{ 2.4 A produção respeita: } \\
\hline & $\begin{array}{l}\text { 2.4.1 A repetição pertinente de ideias/argumentos, de acordo com } \\
\text { a proposta temática da coletânea? }\end{array}$ & $\begin{array}{l}\text { Sim ( ) } \\
\text { Não ( ) } \\
\text { Parcial ( ) }\end{array}$ \\
\hline & $\begin{array}{l}\text { 2.4.2 A relação de ideias, de acordo com a proposta temática da } \\
\text { coletânea? }\end{array}$ & $\begin{array}{l}\text { Sim ( ) } \\
\text { Não ( ) } \\
\text { Parcial ( ) }\end{array}$ \\
\hline & $\begin{array}{l}\text { 2.4.3 A progressão temática, de acordo com a proposta temática } \\
\text { da coletânea? }\end{array}$ & $\begin{array}{l}\text { Sim ( ) } \\
\text { Não ( ) } \\
\text { Parcial ( ) }\end{array}$ \\
\hline & $\begin{array}{l}\text { 2.4.4 A não-contradição, de acordo com a proposta temática da } \\
\text { coletânea? }\end{array}$ & $\begin{array}{l}\text { Sim ( ) } \\
\text { Não ( ) } \\
\text { Parcial ( ) }\end{array}$ \\
\hline \multirow{9}{*}{ 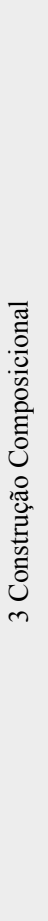 } & \multicolumn{2}{|l|}{$3.1 \mathrm{O}$ texto apresenta: } \\
\hline & 3.1.1 A categoria retórica proposta pelo comando de produção? & $\begin{array}{l}\text { Sim }(\text { ) } \\
\text { Não ( ) } \\
\text { Parcial ( ) }\end{array}$ \\
\hline & 3.1.2 Domínio da capacidade de linguagem que o gênero requer? & $\begin{array}{l}\text { Sim ( ) } \\
\text { Não ( ) } \\
\text { Parcial ( ) }\end{array}$ \\
\hline & 3.1.3 Uma tese em relação ao tema? & $\begin{array}{l}\text { Sim ( ) } \\
\text { Não ( ) } \\
\text { Parcial ( ) }\end{array}$ \\
\hline & $\begin{array}{l}\text { 3.1.4 Argumentos que sustentem a tese, desenvolvidos em } \\
\text { parágrafos distintos (como tópico frasais)? }\end{array}$ & $\begin{array}{l}\text { Sim ( ) } \\
\text { Não ( ) } \\
\text { Parcial ( ) }\end{array}$ \\
\hline & $\begin{array}{l}\text { 3.1.5 Seleção, relação, organização e interpretação de } \\
\text { informações e fatos que justifiquem e comprovem os argumentos } \\
\text { elencados para subsidiar a tese? }\end{array}$ & $\begin{array}{l}\text { Sim ( ) } \\
\text { Não ( ) } \\
\text { Parcial ( ) }\end{array}$ \\
\hline & \multicolumn{2}{|l|}{3.2 O texto: } \\
\hline & $\begin{array}{l}\text { 3.2.1 Não apresenta a categoria retórica proposta pelo comando de } \\
\text { produção: tipologia não compatível com a solicitada no comando. }\end{array}$ & \\
\hline & $\begin{array}{l}\text { 3.2.2 Apresenta marcas frágeis da categoria retórica proposta } \\
\text { pelo comando de produção: tenta marcar uma das categorias } \\
\text { dissertativas - tese, argumentos e conclusão - mas o } \\
\text { desenvolvimento ou parte das categorias entra em outra tipologia. }\end{array}$ & \\
\hline
\end{tabular}




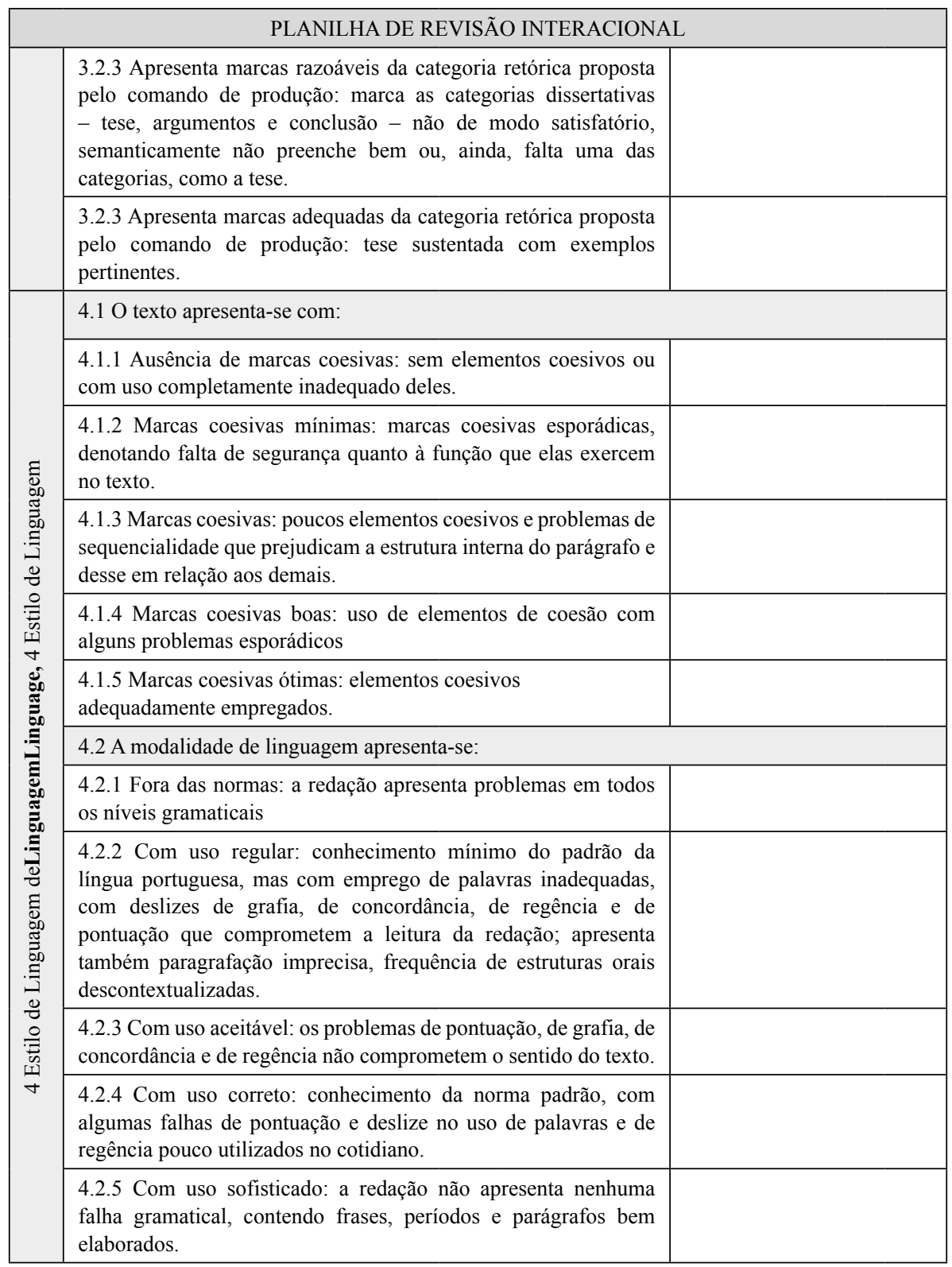


Linguística aplicada: o processo de produção e reescrita textual na educação básica

\begin{tabular}{|c|c|c|}
\hline \multicolumn{3}{|c|}{ PLANILHA DE REVISÃO INTERACIONAL } \\
\hline \multirow{24}{*}{ 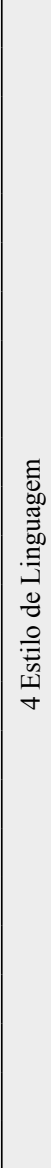 } & \multicolumn{2}{|c|}{ 4.3 Atente-se para os seguintes itens enumerados no texto } \\
\hline & 4.3.1 Ortografia & 4.3.24 Crase (acrescentar) \\
\hline & 4.3.2 Separação silábica & 4.3.25 Crase (retirar) \\
\hline & 4.3.3 Acentuação & 4.3.26 Recursos coesivos (acrescentar) \\
\hline & 4.3.4 Letra legível & 4.3.27 Recursos coesivos (trocar) \\
\hline & 4.3.5 Letra maiúscula & 4.3.28 Sequência lógica (adequar) \\
\hline & 4.3.6 Letra minúscula & 4.3.29 Clareza das ideias (adequar) \\
\hline & 4.3.7 Marcação de parágrafo & 4.3.30 Coerência temática (adequar) \\
\hline & 4.3.8 Ponto final (acrescentar) & 4.3.31 Coerência interna (adequar) \\
\hline & 4.3.9 Ponto final (retirar) & 4.3.32 Repertório linguístico (adequar) \\
\hline & 4.3.10 Vírgula (acrescentar) & 4.3.33 Concordância (corrigir) \\
\hline & 4.3.11 Vírgula (retirar) & 4.3.34 Regência (corrigir) \\
\hline & 4.3.12 Dois pontos (acrescentar) & 4.3.35 Pessoa do discurso (uniformizar) \\
\hline & 4.3.13 Dois pontos (retirar) & 4.3.36 Parágrafo (iniciar) \\
\hline & 4.3.14 Ponto e vírgula (acrescentar) & 4.3.37 Fragmento destacado (adequar) \\
\hline & 4.3.15 Ponto e vírgula (retirar) & 4.3.38 Termo vago (adequar) \\
\hline & 4.3.16 Ponto de interrogação (acresc.) & 4.3.39 Termo incorreto (corrigir) \\
\hline & 4.3.17 Ponto de interrogação (retirar) & 4.3.40 Termo repetitivo (adequar) \\
\hline & 4.3.18 Ponto de exclamação (acresc.) & 4.3.41 Termo desnecessário (retirar) \\
\hline & 4.3.19 Ponto de exclamação (retirar) & 4.3.42 Termo ausente (acrescentar) \\
\hline & 4.3.20 Parênteses (acrescentar) & 4.3.43 Termo deslocado (adequar) \\
\hline & 4.3.21 Parênteses (retirar) & 4.3.44 Termo senso comum (adequar) \\
\hline & 4.3.22 Aspas (acrescentar) & 4.3.45 Título (adequar) \\
\hline & 4.3.23 Aspas (retirar) & 4.3.46 Categoria discursiva (adequar) \\
\hline
\end{tabular}

Fonte: Produção fundamentada em Costa-Hubes (2012b) e Zanini e Menegassi (1999).

Confluência. Rio de Janeiro: Liceu Literário Português, n. 61, p. 434-462, jul.-dez. 2021 
A partir da apresentação da Planilha de Revisão Interacional - PRI, a professora reforça a discussão acerca da produção textual privilegiar o contexto situacional proposto, o conteúdo temático elencado, a construção composicional solicitada e o estilo adequado à situação comunicativa. Além disso, ressalta que, todo texto tem duas versões: a primeira, produzida a lápis, intitulada de Rascunho, e a segunda, preenchida a caneta, chamada de Definitiva, objetivando simular de forma efetiva o gênero Redação do Enem.

A primeira versão escrita é realizada sempre em sala de aula, com a mediação presencial da professora. A segunda, caso não haja tempo para a reescrita em sala de aula, pode ser finalizada em casa. A segunda versão, ao ser entregue, deve estar anexada à primeira versão (a lápis, já analisada e com apontamentos da professora).

A partir dessas orientações, a professora inicia o acompanhamento da produção do texto. Enquanto os alunos escrevem sua primeira versão, na sala, ela faz atendimento e supervisão de cada processo, individualmente. O mesmo procedimento é feito quando se devolve a primeira versão analisada para que os estudantes aprimorem os pontos positivos do texto, bem como procedam na reescrita dos pontos de melhoria. Nessa ação procedimental, a docente perfaz a revisão discursivo-dialógica de aspectos de conteúdo que precisam ser mais bem explorados, sanando as dúvidas que surgem. Nesse curso, o processo das revisões trata dos aspectos pertinentes ao estudo do gênero discursivo, tanto de aspectos constitutivos quanto orgânicos da produção.

\section{Revisão discursivo-dialógica no processo de produção e reescrita textual}

Com o intuito de delimitar a pesquisa, focaliza-se na produção e na reescrita textual de um estudante, partícipe de todo o processo de produção textual e de revisão interacional, conforme discriminado na seção anterior: 


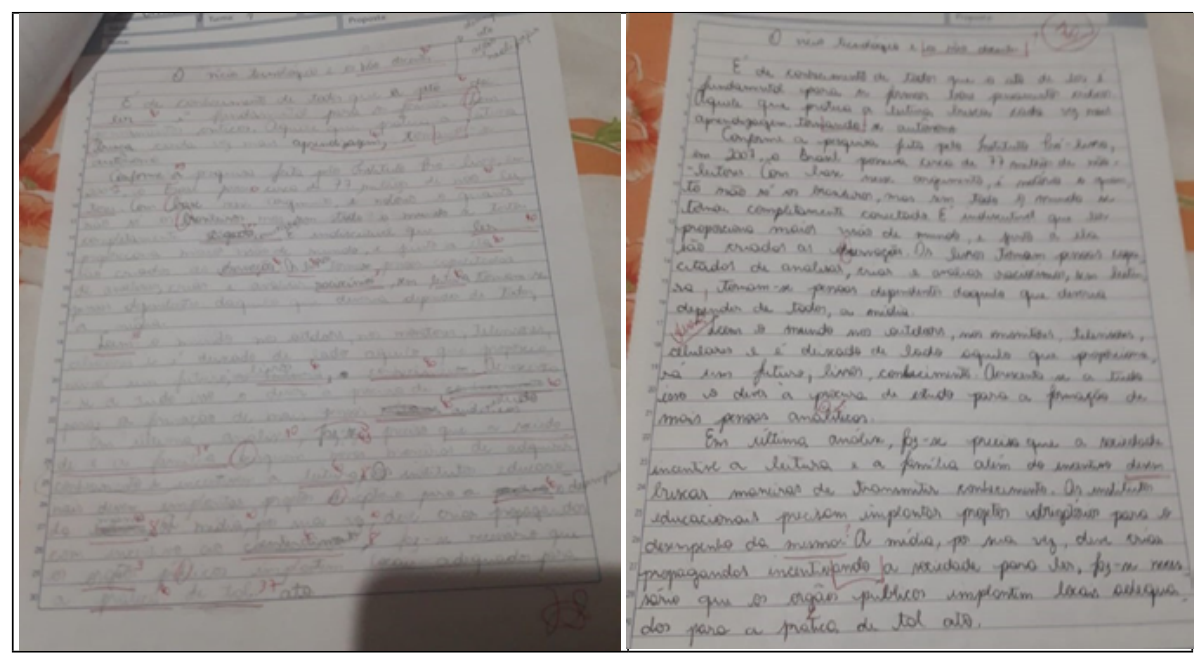

Figura 3. 1. e 2. ${ }^{\mathrm{a}}$ versão da produção textual do estudante

A partir da revisão realizada por meio da PRI, ressalta-se que, em sua primeira versão, o discente atende ao contexto de produção, pois seu texto:

a) trata de um texto-enunciado do gênero solicitado pelo comando (PRI - item 1.11);

b) atende a necessidade de interação estabelecida (PRI - item 1.12);

c) apresenta uma linguagem parcialmente adequada ao contexto de produção (PRI - item 1.13);

d) identifica no texto os interlocutores (PRI - item 1.14);

e) reconhece, no texto, de forma genérica o tema solicitado (PRI item 1.15);

f) distingue-se, ao longo do texto, o posicionamento ideológico defendido pelo produtor do texto (PRI - item 1.16). 
Em relação ao conteúdo temático, o partícipe atende à temática abordada pela coletânea Leitura, pensamento crítico e autonomia, uma vez que apresenta:

a) produção que respeita a repetição pertinente de ideias/ argumentos, de acordo com a proposta temática da coletânea (PRI - item 2.4.1);

b) relação de ideias (PRI - item 2.4.2);

c) progressão temática (PRI - item 2.4.3).

Contudo, precisa de alguns aspectos de melhoria em determinados itens, pois o/a:

a) título está impertinente, uma vez que foge ao tema (PRI - item 2.11);

b) leitura pode melhor, uma vez que desenvolve o tema completo, acrescentando informação nova, mas fundamenta-a no senso comum (PRI - item 2.2.4).

c) tese pode melhorar, pois a argumentação não apresenta elaboração adequada (PRI - item 2.3.3).

A construção composicional corresponde à solicitada pelo comando, haja vista que o estudante:

a) apresenta a categoria retórica proposta pelo comando (PRI item 3.1.1);

b) demonstra o domínio da capacidade de linguagem que o gênero requer, mesmo que parcialmente (PRI - item3.1.2);

c) defende uma tese em relação ao tema (PRI - item 3.1.3);

d) expõe argumentos que sustentam a tese, desenvolvidos em parágrafos distintos (PRI - item 3.1.4);

e) faz seleção, relação, organização e interpretação dos argumentos elencados para subsidiar a tese (PRI - item 3.1.5);

f) mostra marcas razoáveis da categoria retórica proposta pelo comando (PRI - item 3.2.3). 
Já quanto ao estilo de linguagem, na primeira versão, o estudante:

a) apresenta marcas coesivas mínimas ou esporádicas, denotando falta de segurança quando à função que elas exercem no texto (PRI - item 4.1.2);

b) utiliza um repertório linguístico de uso regular (PRI - item 4.2.2).

Na segunda versão, depois das observações da professora em relação aos aspectos que precisam ser revistos pelo discente, o estudante, produtor do texto, atenta-se para os apontamentos, resultando no aprimoramento:

a) da modalidade de linguagem que se torna satisfatória ao contexto de produção (PRI - item 4.2.3) .

b) da argumentatividade, pois apresenta tese, argumentação que extrapola o texto de apoio, embora ainda faltem marcas de tentativa de persuasão do leitor ao final (PRI - item 3.2.3).

c) do estilo de linguagem, porque o discente apresenta um avanço com marcas coesivas boas, apesar de alguns problemas esporádicos (PRI - item 4.1.4).

Em síntese, ao realizar a reescrita do texto, com base na revisão classificatória interativa, o estudante apresenta melhorias. Além disso, demonstra a apreensão dos elementos constitutivos e orgânicos do gênero Redação do Enem. Todavia, ao não atender parte das recomendações docentes que exigem ações mais complexas, relativas principalmente à argumentatividade do texto, apresenta limitações, justificadas, talvez, pelo tema que tende mais à abstração; às eventuais idiossincrasias do produtor do texto que resultam na subjetividade inerente a cada produtor/escritor, bem como a suas limitações; ou até a falta de outras estratégias didáticopedagógicas que pudessem subsidiar o estudante de melhor forma. 


\section{Considerações finais}

É possível refletir, a partir do estudo realizado, que a escrita pode ser privilegiada como processo quando se pauta a aprendizagem na concepção dialógica e interacional de língua(gem). Constata-se que melhorias na maneira de compreender o desenvolvimento do estudante são passíveis de acontecer, ao se fortalecer o aprimoramento das capacidades linguístico-discursivas. Devese apreender que o encaminhamento, a produção, a revisão e a reescrita textual são etapas que compõem o caminho para a re(construção) do texto autoral.

Nesse sentido, realiza-se o estudo teórico da ADD, em relação aos elementos constitutivos dos textos-enunciados e gênero discursivo, principalmente no que concerne ao texto-enunciado produzido pelos estudantes; reflete-se acerca do processo de escrita e de reescrita, seguindo os preceitos da LA; observa-se, de maneira descritivo-analítica, o processo de produção e de reescrita textual na Rede Básica de Ensino.

Pode-se, por meio dessas ações, compreender que a revisão discursivodialógica, juntamente com a proposta da PRI, permite à docente mediar o processo de (re)escrita de forma a propiciar a melhoria do texto do estudante, sujeito da investigação. Ademais, o planejamento da ação docente juntamente com o encaminhamento de produção textual estimulam condições necessárias para a escrita discente. Logo, tal proposta mostra-se como um caminho possível ao trabalho docente no EM, conforme preconizam os documentos norteadores da Educação Básica - DCE de Língua Portuguesa (Paraná, 2008), que visa a uma proposta dialógica e interacional de língua(gem).

\section{Referências}

BAKHTIN, M. (1979). Estética da criação verbal. 4. ed. São Paulo: Martins Fontes, 2009.BAKHTIN, M.;VOLOCHÍNOV, M. (1929). Marxismo e filosofia da linguagem. Tradução Paulo Bezerra. 4. ed. São Paulo: Martins Fontes, 2003. 
BORTONI-RICARDO, S. M. O professor pesquisador: introdução à pesquisa qualitativa. São Paulo: Parábola Editorial, 2008.

COSTA-HÜBES, T. C. 2012 a. Reflexões sobre os encaminhamentos de produção textual: enunciados em diálogo com outros enunciados. In: Encontro do CELSUL - Círculo de Estudos Linguísticos do Sul, Cascavel, 2012. Anais ... Cascavel, CELSUL. p. 1-15.

COSTA-HÜBES, T.C. 2012 b. Análise de textos de alunos dos anos iniciais: orientações para um possível diagnóstico. In: Working Papers em Linguística. Anais ... Florianópolis, UFSC. p. 01-20.

COSTA-HÜBES, T. C. Os gêneros discursivos como instrumentos para o ensino de Língua Portuguesa: perscrutando o método sociológico Bakhtiniano como ancoragem para um encaminhamento didáticopedagógico. In: NASCIMENTO, E. L.; ROJO, R. H. R. (org.). Gêneros De Texto/Discurso e os Desafios da Contemporaneidade. Campinas: Pontes Editores, 2014. p. 13-34.

ERICKSON, F. Prefácio. In: COX, Maria Inês P. \& ASSIS-PETERSON (Org.). Cenas de Sala de Aula. São Paulo: Mercado de Letras, 2001, p. 9-17.

FABRE, C. Des variantes de brouillon au cours préparatoire. Études de Linguistique Appliquée, 1986, p.59-79, Avril-Jun.

GERALDI, J. W. Portos de Passagem - texto e linguagem. 4a ed. (É 4.) São Paulo: Martins Fontes, 1997.

KRAEMER, M. A. D.; COSTA-HÜBES, T. C.; LUNARDELLI, M. G. A Linguagem e sua Natureza Ideológica. In: FRANCO, N.; PEREIRA, R. A.; COSTA-HÜBES, T. C. Estudos dialógicos da linguagem: reflexões teóricometodológicas. São Paulo: Pontes Editores, 2020, p. 63-88.

LUCENA, A. M. S; SARAIVA, E. S. S; ALMEIDA, L.S.C. A. Dialógica como Princípio Metodológico Transdisciplinar na Pesquisa em Educação. Millenium, jan/jun, 2016, p. 179-196. 
MENEGASSI, R. J. O processo de produção textual. In: SANTOS, A. R. dos; GRACO, E. A.; GUIMARÃES. T. B (Orgs.). A Produção Textual e o Ensino. Maringá: Edue, 2010, p. 75-102.

MENEGASSI, R. J. Escrita como trabalho na sala de aula. In: JORDÃO, C. M. (Org.). A Linguística Aplicada no Brasil: rumos e passagens. São Paulo: Pontes Editores, 2016, p. 193-230.MOITA LOPES, L.P. Linguística Aplicada e Vida Contemporânea: Problematização dos Construtos que Têm Orientado a Pesquisa. In: MOITA LOPES, L.P. Por uma Linguística Aplicada Indisciplinar. São Paulo: Editora Parábola, 2006, p. 85 - 105.

PARANÁ. Secretaria de Estado da Educação. Diretrizes Curriculares da Educação Básica: Língua Portuguesa. Curitiba: SEED, 2008.

PERFEITO, A. M. 2010. Concepções de linguagem, teorias subjacentes e ensino de língua portuguesa. In: MENEGASSI, R. J.; SANTOS, A., R. dos; RITTER, L. C. B. (Org.). Concepções de linguagem e ensino. Maringá: Eduem, p. 11-40. (Coleção formação de professores EAD).

PEREIRA, T. H.M. Práticas da produção textual: $2^{\text {a }}$ Série/ Thais Helena Miguel Pereira/ Georgia Fabiana Mendes Marinho (Org).- 9 ed. Fortaleza: Sistema Ari de Sá de Ensino, (Coleção Integrada), 2018.

REBOUL, O. Introdução à Retórica. Trad. Ivone Castilho Benedetti. 2. ed. São Paulo: Martins Fontes, 2004.

REIS, M. F. C. T. A pesquisa e a produção de conhecimentos. In: Introdução à Pesquisa Científica em Educação. Botucatu: Unesp, 2009.

RUIZ, E. D. Como Corrigir Redações na Escola. $3^{\text {a }}$ (É 3.)reimp. São Paulo: Contexto, 2015.

SERAFINI, M.T. Como Escrever Textos. Trad. Maria Augusta Bastos de Mattos, São Paulo: Globo, 1989. 
SIGNORINI, I.; CAVALCANTI, M. C. (Org.). Linguística Aplicada e Transdisciplinaridade: questões e perspectivas. Campinas: Mercado de Letras, 2004.

SIMONI. C.A. A Sequência Didática como Proposta de Trabalho com os Gêneros Discursivos: relato descritivo-crítico de uma experiência. Dissertação (Mestrado em Letras), Universidade Estadual do Oeste do Paraná, Cascavel, 2012.

SOBRAL. A.; GIACOMELLI, K. D. Das Significações na Língua ao Sentido na Linguagem: parâmetros para uma análise dialógica. Linguagem em (Dis) curso - LemD, Tubarão, 18, 2016, p. 307-322.

SOBRAL. A. Entrevista Especial IV. O consoante - produção do grupo Gênese (Gêneros em situação de escrita). Disponível em: http://oconsoante. com.br/2019/04/09/entrevista-especial-vi/. Acesso em: 30 jul. 2019.

TRIPP, D. Pesquisa-ação: uma introdução metodológica. In: Educação e Pesquisa, São Paulo, 2005, p. 443-466.

TRIVINÕS, A. N. S. Introdução à pesquisa em Ciências Sociais: a pesquisa qualitativa em educação. São Paulo: Atlas, 1987.

VOLOCHINOV, V. N.; BAKHTIN, M. Discurso na vida e discurso na arte: (sobre poética sociológica). Tradução de Carlos Alberto Faraco e Cristóvão Tezza [para fins didáticos]. 1926. Versão da língua inglesa de I. R. Titunik a partir do original russo.

ZANINI, M.; MENEGASSI, R. J. Avaliação de redação: o tema. In: do X Seminário do Centro de Estudos Lingüísticos e Literários do Paraná, Londrina. Anais... Londrina, X CELLIP. 1997, p. 43-51.

Avaliação de redação: proposta de uma planilha. In: XI Semana de Letras, 1999, Maringá. Anais Outras Palavras- XI Semana de Letras. 1999, p. 437-445. 